\title{
PRESENT STATUS OF CORTICOTROPIN (ACTH), CORTISONE, AND HYDROCORTISONE IN OPHTHALMOLOGY*†
}

\author{
BY \\ DAN M. GORDON, JOHN M. MCLEAN, AND HERBERT KOTEEN \\ From the Departments of Surgery (Ophthalmology) and Medicine, \\ New York Hospital, Cornell Medical Center
}

IN previous communications (Gordon and McLean, 1950; McLean and others, 1951; Gordon and others, 1951) this group has reported its experiences in the treatment of ocular disease with the use of corticotropin (ACTH) and cortisone. The present paper summarizes our knowledge of the clinical use of corticotropin and cortisone in ophthalmology and adds experiences with hydrocortisone during the past year.

Nearly 3 years have elapsed since the introduction of these hormones into the ophthalmic armamentarium, but acquaintance with their uses, abuses, and limitations is not yet universal. Most ophthalmologists have had experience with the topical application of cortisone in drops or as an ointment, and many have used it systemically by intramuscular injection and orally in tablet form, but comparatively few have employed corticotropin. Too many physicians are still afraid to use corticotropin, or even cortisone by injection; but they occasionally use cortisone orally because they have the naive belief that anything given by mouth cannot be very dangerous.

A recent survey conducted for one of the manufacturers: by an independent testing company indicates that only 2 per cent. of ophthalmologists are familiar with the use of corticotropin. Even allowing for a great error in this analysis the final percentage would remain relatively small. One of the chief reasons for not using this potent hormone is the fear of the side-effects which systemic medication may produce. This same fear has undoubtedly militated against the use of cortisone systemically where systemic therapy has been indicated; or has resulted in the use of inadequate doses.

It is unfortunate that the therapeutic horizon of too many ophthalmologists ends with the use of cortisone by topical application. While the topical applications of cortisone are very efficient, where indicated, they are equally impotent where not indicated, and an excellent mode of therapy may be discredited by improper use.

The use of cortisone topically as the primary procedure in treating superficial ocular disease is usually highly efficient. Cortisone drops or ointments are at times valuable in the initial treatment of uveitis, but one cannot count

* Received for publication September 26, 1952.

+ Supported in part by a research grant from the National Institutes of Health, Public Health Service, and by a grant from the James Foundation of New York, Inc.

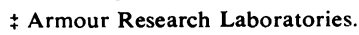


on their being consistently successful in intra-ocular disease. In many cases where the disease has responded to intensive treatment with subconjunctival cortisone or systemic corticotropin or cortisone, the topical applications may then prove valuable in the secondary control of the disease.

As a rule there is some intra-ocular absorption of topically applied cortisone. Sometimes this amount is insufficient to control an acute intra-ocular disease, but may suffice in the secondary control.

Subconjunctival injections of cortisone, with or without support by topical applications are often sufficient in anterior uveitis, and less frequently so in posterior segment disease, and in both, as noted later, an initial short course of systemic therapy may be valuable or essential.

In the treatment of inflammatory disease of the posterior globe or of severe anterior segment disease which has not responded to topical or subconjunctival cortisone, systemic therapy is certainly indicated. If the patient is receiving ambulatory treatment, oral or intramuscular cortisone or intramuscular injections of corticotropin in the new long-acting vehicles are very useful. The new "gel" forms of corticotropin lend themselves to ambulatory use, as each injection is effective for at least 24 hours. It must be emphasized that many of the conditions which were formerly considered suitable for hospital treatment only, can now be handled on an ambulatory basis, if arrangements can be made for the patient to receive injections at home from a member of the family or a visiting nurse.

If the patient requires hospitalization the use of corticotropin in a prolonged intravenous drip is the most efficient weapon available (Woods, 1952). According to Thorn (1952), $25 \mathrm{mg}$. corticotropin administered intravenously in an 8-hr. drip is equivalent to $300 \mathrm{mg}$. cortisone.

The medical and lay public have been unduly frightened by some of the statements regarding complications which have been publicized. It was brought out at the Third ACTH Conference (Gordon, 1952; Smith, 1952; Wolfson, 1952) that healthy individuals suffering from a disease of an isolated organ such as the eye do not tend to develop the more serious complications (such as gastro-intestinal perforations) which are seen in a relatively small percentage of patients suffering from systemic illness. In the past ophthalmologists have had little experience with therapeutic agents having systemic as well as local effects but now, unless they take the trouble to study these compounds in co-operation with a specialist in internal medicine, they may deprive their patients of many of the advantages of present-day therapy.

These hormones are most efficient in the treatment of ocular disease when they are employed very early during the stage of acute inflammation. The compound selected should be given promptly and in doses large enough to meet the situation. There is apparently a definite relationship between the severity of the disease process and the amount of corticotropin or cortisone necessary to overcome it. It is possitle to meet an inflammation of such 
severity that neither corticotropin nor cortisone can achieve the desired result, but one cannot admit failure in any given case until both hormones have been tried by various routes. Further, as more potent preparations are becoming available, fewer failures should occur. The following case history illustrates this point.

\section{Case Report}

A male patient with acute optic neuritis of 3 weeks' duration was admitted on March 4, 1952, with vision of light perception superiorly in the right eye and 20/15-2 in the left. In June, 1950, he had had a similar loss of vision on the right, with later loss of vision on the left, followed by improvement in both eyes. He is a suspected but unproved case of multiple sclerosis. He was placed on intravenous corticotropin, $25 \mathrm{mg}$. daily for 7 days, increased to $50 \mathrm{mg}$. daily for an additional 6 days. Vision in the right eye was then $3 / 200$. In the interim vision in the left eye had regressed to $20 / 40$ as this disk began to assume the typical picture of optic neuritis. The corticotropin was discontinued and cortisone given in doses of $50 \mathrm{mg}$. every $6 \mathrm{hrs}$, for 2 days. His vision now was counting fingers at 3 feet, 20/40. The authors had just been requested to supply data on a new preparation of corticotropin in a long-acting vehicle, which the manufacturer thought more potent than those then being used by our group. The patient was given 40 units of this preparation twice daily, for 10 days, when the dose was halved for 2 days and then reduced to 10 units, twice daily, for 2 more days before being discontinued. On the second day his vision was $3 / 70$ in the right eye, improving to $20 / 160$ by the third, $20 / 70$ on the sixth, $20 / 40$ on the ninth, and $20 / 30$ on the eleventh day. The vision in the left eye remained at $20 / 40$ until the ninth day on the new preparation when it was recorded at 20/30, uncorrected. This patient has not relapsed (as at June 1, 1952).

It is recognized that these agents do not affect the underlying cause of the disease; and are at their best when employed in the treatment of acute self-limiting conditions. Prompt and judicious use of corticotropin or cortisone in the treatment of an acute ocular disease or allergic reaction will usually result in the subsidence of the inflammation and thus prevent destruction of vital ocular tissue. Meanwhile the pathogenic process burns itself out. Failure to continue the hormone long enough for the acute pathogenic process to run its normal course will result in relapses demanding reinstitution of therapy. Fear of either corticotropin or cortisone by the physician who regards them as drugs of last resort, to be used only when everything else has failed, often means that the disease process is given time to become chronic. The patient is now faced with a long, or even permanent, period of treatment, whereas the disease could possibly have been aborted rapidly had hormonal treatment been instituted at its onset. An analysis of failures with hormonal-steroid therapy makes it clear that most of these are due to " too little", or " too late", or both.

Nor should the advent of corticotropin and cortisone be a signal to discard all previous agents employed in the handling of inflammatory eye disease. Some of these may serve to speed up the convalescent period so saving the amount of hormone employed. Atropine, fever therapy, and antibiotics continue to have a prominent place in the treatment of ocular disease, when indicated.

Atropine certainly still merits use in the treatment of the uveitides, putting the eye at rest, and making examination easier.

Randolph and Rollins (1950), Arendshorst and Falls (1950), and Rosen (1952) have shown that artificial fever therapy apparently functions at least partially via the release 
of adrenocorticotropic substances. There seems to be no real reason for using fever therapy simultaneously with corticotropin or systemic cortisone, but the two methods can be employed on alternate days where the patient seems to be developing hormonal side-effects (moon-face, etc.). Again, a course of fever therapy can be employed as part of the tapering off process at the end of a course of corticotropin or cortisone or as part of maintenance therapy in a chronic inflammatory disease.

Either corticotropin or cortisone may prove excellent in the treatment of the inflammatory phase of eye infections without any appreciable effect upon the causative organisms which continue to be present. Conversely the indicated antibiotic often fails to clear up the symptoms of disease. A combination of the hormone, which suppresses the inflammatory reaction, and the antibiotic, which " sterilizes" the area, frequently gives an excellent visual result and may shorten the period of convalescence.

It has been demonstrated (Leopold, 1951) that certain antibiotics (e.g., penicillin) will not penetrate the ocular tissues in appreciable quantities in the presence of normal capillary permeability. When this is altered as in ocular inflammation these antibiotics will be found in concentration and can function therapeutically, but since they suppress the ocular inflammation and cause a return to normal capillary permeability, they cease to be able to enter the ocular tissues. Certain other antibiotics such as chloramphenicol, however, are exceptions to this statement. Therefore, in the presence of severe ocular infection where the use of antibiotics is desirable, either one must not employ corticotropin or cortisone or one must use with them an antibiotic which will continue to be effective in their presence.

Either corticotropin or cortisone may produce a similar therapeutic result in the average case of ocular inflammation or allergy, but since these are two very different compounds functioning via two different mechanisms, they may produce different results in the same patient.

It was thought formerly that corticotropin functioned primarily through the stimulation of cortisone-like substances, but it is now apparent as a result of the work with hydrocortisone that this is not entirely the case. By virtue of the fact that it stimulates the entire adrenal cortex and other structures as well corticotropin has a much broader spectrum of action than cortisone. Therefore, if either fails in the treatment of any eye disease, one must not assume that the other will fail also. On the contrary, such failure is to be regarded as a signal for the use of the alternate compound.

It is our practice at the New York Hospital to give an acute case of ocular inflammation a trial period of not more than 48 to $72 \mathrm{hrs}$ on the hormone previously selected. Experience has indicated that in the average case a beneficial response will be noted within $24 \mathrm{hrs}$, but if a good response is not seen within $72 \mathrm{hrs}$, it is assumed that the patient is either not receiving enough of the hormone or is a subject for the alternative hormone. If he is on a moderately low dose, the amount is increased. If this fails, or if he is already on a large dose (e.g., $300 \mathrm{mg}$. cortisone daily), he is switched to the other compound.

In all cases the measurement of the circulating eosinophils and the response of the disease process are the chief guides to dosage, subject to the appearance of side-effects. These last have been discussed at such length in the literature that it suffices here merely to enumerate them (Table I, opposite). As our experience with these compounds systemically has increased, fewer and fewer complications have been noted. It is obvious that this is the result of improvement in management and in ability to note the onset of side-effects early.

\section{Treatment of Chronic Disease}

When one meets with a chronic inflammatory disease or has permitted an acute disease to become chronic, a different situation results. Experience has shown that the chronic inflammatory or allergic eye disease cannot be 
TABLE I

IMPORTANT MEDICAL ASPECTS OF POSSIBLE SIDE-EFFECTS

Complications of Systemic Therapy

Retention of sodium chloride and water

Marked elevation of blood pressure

Low serum potassium and hypochloraemic alkalosis

Hyperglycaemia and glycosuria

Major psychotic changes

Signs of Cushing's disease: acne, hirsuitism, plethora, striae, fat pads

Pigmentation of skin and nails

Anaesthetic reaction (reduction in pain threshold)
Management

Weigh daily; if sudden increase in weight is noted, restrict salt and/or use diuretics

Follow daily pressure; if severe continuing hypertension is present therapy may have to be stopped

Follow EKG for potassium changes and serum for changes in $\mathrm{CO}$, and chlorides; oral potassium chloride ( $3 \mathrm{~g}$. daily) prevents these changes usually

Important in diabetics and suggests need for more insulin

Watch for manic, depressed, schizoid alterations; if severe, stop therapy

These disappear on termination of hormonal therapy and are no contraindication

A rare, cosmetic problem of no consequence

Rarely, there may be painless perforation of a viscus without fever; locate air below diaphragm and operate

aborted completely by hormonal treatment, for when the treatment is stopped the disease will shortly return. Occasionally however a long period of remission will occur. Whether it would have also occurred spontaneously at the same time is not always certain. However, the use of either one of these compounds during the chronic or recurring phase will, when successful, prevent the occurrence of damage. Since many chronic diseases tend to have remissions it behoves the ophthalmologist to protect the chronically inflamed eye as far as possible pending the onset of such a remission. Further, in these days of rapid advances in therapy one never knows when some superior method of treating chronic diseases will be found. Should such an event ensue, the eye which has been kept in an optimal condition, will be in the best position to be benefited. In our experience relapses require less hormone over a shorter period in order to produce a remission. This is contrary to the experience of Duke-Elder (1951).

The management of chronic inflammatory or allergic eye disease is very difficult. The regime here is based on the principle that, once the severe manifestations of the inflammation have been suppressed by intensive systemic treatment, they can be held in a state of suppression, frequently by less intensive therapy. The ideal case would be one which could be controlled by topical cortisone, after initial suppression by systemic therapy. Unfortunately, such cases are rare. It is our usual practice to hospitalize the patient with chronic inflammatory disease and to give him a course of 
$\mathrm{ACTH}$ by intravenous drip, the length of hospitalization being regulated by the patient's response. Once the severe symptomatology has subsided, the dosage is tapered off, and measures are instituted to render him ambulatory. The next step is to work out a maintenance dosage harmonizing the maximum safety for the patient and the minimum damage to the eye, that is the least amount of the indicated hormone and the maximum interval between treatments. If the chronically affected eye can continue safely with local therapy alone that is obviously the procedure of choice, but we have found that many such patients require systemic therapy, at least early in the course of treatment, either with corticotropin in one of the long-acting vehicles or with cortisone. The newer forms of corticotropin in long-acting vehicles lend themselves especially well to ambulatory treatment, as does cortisone orally. We have not hesitated to bring the patient back into the hospital for an occasional week-end of intensive intravenous corticotropin therapy and we have also employed fever therapy as an adjunct to the treatment of chronic eye disease. In some cases which seemed to fit our concept of ocular tuberculosis, isonicotinic acid was used. It is still too early to comment on the results of this therapy which had seemed promising in at least two cases, despite later relapses. Some of our long-term chronic cases have shown a need for less and less medication after long periods on hormonal therapy. This treatment is too new for anyone to be sure whether a chronic inflammation will or will not burn itself out on long-term treatment but one should do one's best to preserve these eyes as long as possible. Some of our patients who have been treated successfully for 1 or 2 years have only one eye.

Woods (1951), and Woods and Wood (1951) have reported on the deleterious effects of these agents when employed in the treatment of experimentally produced ocular tuberculosis with one possible qualification. These results have not been duplicated in our clinical practices. A small number of cases have done poorly when treated with local or systemical cortisone, but nearly all of them responded well to corticotropin. The whole question of the relation of these two hormones to tuberculosis, either local or systemic, has yet to be resolved. Apparently, the available evidence indicates that corticotropin is safer than cortisone in the presence of tuberculosis, but that neither is as yet proved to be clinically dangerous (Tompsett, 1952).

The numerous case reports in the literature render it unnecessary to include any statistical analysis here. Woods has compiled the findings at both the New York Hospital and Johns Hopkins Hospital (Wilmer Institute), and has commented on the marked similarity in results. Other large series, such as those of Duke-Elder, show similar trends.

Much of the earlier literature is very confusing and paradoxical because most papers were based on relatively few cases. Some failures were due to the fact that only local cortisone was used, and others to the relatively 
minute doses or to the lateness of the institution of hormonal therapy. The failure to use potassium chloride together with systemic medication caused many side-effects. Occasionally, an insufficiency of potassium will result in retinal oedema with a decrease in vision in the presence of sufficient hormone. Potassium chloride can be used in doses up of to 12-15 g. daily. The present trend is towards increasingly large doses of this salt. The indication for the early use of either corticotropin or cortisone is any acute inflammatory or allergic disease of the eye or ocular adnexa, for which specific therapy is not available. Where specific therapy is indicated, as for example in syphilitic infection, it may be employed either alone or in conjunction with hormonal therapy.

The retardation of healing said to be caused by both corticotropin and cortisone, has been over-dramatized, since, in most cases, the amount of hormone employed experimentally exceeded that generally used in ophthalmic therapy. Where healing is a factor, it is probably best not to use cortisone or corticotropin until about 10 days after intra-ocular surgery. However, if one is trying to prevent the scarring down of a bleb in a filtering operation, then early judicious use of local cortisone is indicated, as also in unusually severe post-operative reactions. A number of patients have had ocular surgery while receiving corticotropin or cortisone (Thorpe, 1951) without any apparent interference with healing. The present authors have seen one temporary delay in healing after starting topical cortisone on the third post-operative day; when the cortisone was discontinued the wound healed without further delay or complication. However, it is wise to remember the possibility of a delay in healing and to use precautions, such as extra sutures, etc. In the treatment of chorio-retinitis certain cases will heal with a "smear" instead of the usual clean cut scar, and will practically always have recurrences some time after the cessation of treatment. Relapse may be prevented by prolonging the course of therapy with either subconjunctival or systemic treatment, or by employing artificial fever. The treatment here should be continued until a pigmented or " hard " scar is obtained.

One of us had the opportunity of seeing a small number of cases of severe corneal ulceration due to pseudomonas infection thought to have been traced to contaminated solutions of cortisone. In all but one of these cases, the patient was immediately taken off the cortisone and put on antibiotic therapy, and all did poorly. The one exception was hospitalized and treated with a different mixture of cortisone in addition to antibiotics, and this was the only patient who did well. The combination of the indicated antibiotic with hormonal therapy is often superior to either agent alone.

We have used cortisone and sodium sulphacetamide* for the past year; and have found it efficient. The sulphacetamide serves a two-fold purpose:

(i) It combats infection.

(ii) It serves to render the solution sterile. 
Technically, the sterilization of cortisone "drops" has proved difficult, but the addition of an antibiotic serves to prevent contamination.

The authors have also employed combinations of cortisone and an antihistaminic* ("Chlor-Trimetron") in local allergies. The addition of the antihistamine has made it possible to use weaker solutions of cortisone ( 0.25 per cent.), and the combination has proved successful.

Perhaps the chief contraindication to the use of these agents in ocular inflammatory disease is infection with the various viruses. Here for the most part results have been poor, with only a very occasional good. These agents have very little, if any, influence in either direction upon the bleeding retinopathies such as diabetic retinopathy and Eales's disease. One of our two cases of Eales's disease treated with corticotropin felt that she afterwards had a longer period of freedom from ocular bleeding. The same patient had profuse ocular bleeding after two different trial weeks of oral isonicotinic acid therapy.

\section{Experimental Observations}

Corticotropin and cortisone differed from the many new therapies in that considerable clinical experience was accumulated before much laboratory data was available. The latter is now beginning to corroborate and explain most of the clinical results, though much remains to be done.

All ocular inflammations are accompanied by an increase in capillary permeability, which is an important feature of the exudative process. These hormones do not affect capillary permeability in the normal eye, but in the inflamed eye have the power to reduce it to normal (Ashton and Cook, 1951; Cook and MacDonald, 1951; Leopold and others, 1951), which helps to explain the dramatic response of the acutely inflamed eye to these compounds. In wounds in experimentally treated animals practically no exudate and fibrin is seen $24 \mathrm{hrs}$ after wounding or the application of croton oil (Michael and Whorton, 1951). Biegel (1951) produced horse serum uveitis in rabbits and noted that cortisone inhibited the formation of plasmoid aqueous and fibrin in the anterior chamber.

Selye (1950), Woods and Wood (1951), Biegel (1951), and other workers have shown that these compounds have a marked inhibitory effect upon experimentally produced allergic and inflammatory reactions. Certain substances will produce such reactions in untreated experimental animals, but no such reactions occurred when they were first pre-treated with hormones. Woods and Biegel have each demonstrated that the hormones block the result of antigen-antibody reaction in ocular tissue.

The present authors have reported on a similar clinical case. The patient was a boy with confirmed sympathetic ophthalmia, who was given an uveal pigment skin test while under treatment with corticotropin; when the injected area of skin was eventually biopsied no cellular reaction was noted.

* Supplied by the Schering Corporation. 
Cortisone also inhibits corneal neovascularization. Clinically, this is best demonstrated by subconjunctival injections of approximately $8 \mathrm{mg}$. cortisone at the sites of the new vessels. Topical applications were effective, and same results were obtained with hydrocortisone.

Leopold and others (1951) demonstrated that cortisone inhibited corneal epithelial regeneration, after the production of standard abrasions. The present authors were first stimulated to use cortisone topically in ocular disease by the reports of Baker (1949) and Baker and Castor (1950), to the effect that cortisone prevented regrowth of hair when applied to the skin of rats. Various reports concerning the action of cortisone on wound healing and mitosis have been somewhat at odds with each other, on account of variations in dosage; when large concentrations were used healing was retarded, but with moderate amounts this result was not significant.

Ashton and Cook (1951) and Lister and Greaves (1951) found that cortisone in small doses did not appreciably retard epithelial regeneration in standard corneal abrasions, but that there was inhibition with larger doses. They did find a decrease in endothelial regeneration of rabbits' corneae under cortisone, but it did not seem marked enough to be important.

In animals it has been demonstrated that the formation of connective tissue in wounds and inflammations is delayed by cortisone, and that thus healing is retarded (Plotz and others, 1950; Ragan and others, 1950). Similar observations in man have been contradictory and showed less delay; the dosage used in the experiments was far greater than that used clinically.

Steen (1951) has shown that when cortisone was employed in a concentration equal to 25 times that used clinically there was no inhibition of mitosis or growth in tissue cultures.

\section{Related Compounds}

Our experiences with $\triangle$-5-pregnenolone and 21-acetoxypregnenolone in a series of 31 cases with degenerative and inflammatory ocular disease failed to demonstrate any activity on the part of these two compounds.

The melanophore hormone has been employed in our clinic in a series of patients with either retinitis pigmentosa or diabetes. As will be reported in a separate communication, we failed to obtain the dramatic results reported by Steffensen and Kukora (1951) or Gonzalez Vanrell and others (1949).

The recent findings commented upon in the Journal of the American Medical Association (1952) that placental tissue and extracts possess adrenocorticotropic activity remind us of previous experiences with " tissue therapy" (Gordon, 1947; 1948)

\section{Hydrocortisone}

17-hydroxycorticosterone (Compound F), the newest of the steroid hormones to be introduced to ophthalmology, is used both as an acetate and in the free alcohol form. Though the authors have used it for almost a year, they feel that the range of application is not yet complete.

Hydrocortisone has been employed in a series of sixty cases much in the same manner and in the same dosages as cortisone; in 0.5 and 2.5 per cent. 
suspensions topically, $15 \mathrm{mg}$./g. as an ointment, $8 \frac{1}{3}-12 \frac{1}{2} \mathrm{mg}$. subconjunctivally, and 100-125 mg. intramuscularly or orally daily. Systemically it appears to be more effective than cortisone in lesser concentrations (Alpert, 1952). Topically, its analgesic effect is the same or greater than that of cortisone. Administered subconjunctivally, it provokes less local reaction than cortisone. The acetate crystals remain in the subconjunctival space for a much longer period than cortisone and the free form absorbs overnight; both forms cause a local reaction similar to cortisone.

Vernal Catarrh.-Topically, hydrocortisone acetate has proved far superior to cortisone in three cases:

(1) Relapse occurred within 1 or 2 days in one of these patients after withdrawal of cortisone (topical and oral), but on the two occasions when hydrocortisone was used did not occur until 10 and 14 days respectively. This patient ( a boy) required topical plus oral cortisone for good control, but a similar response was obtained with topical hydrocortisone alone.

(2) A second boy had previously been treated unsuccessfully with topical and systemic cortisone, as well as beta irradiation; his response to topical hydrocortisone used in drops and ointment was excellent, but relapse occurred four days after withdrawal.

(3) The third patient, who had not had cortisone previously, responded rapidly to topical hydrocortisone.

Local Lid Allergy.-Five cases responded promptly to topical applications of hydrocortisone acetate. A very severe case of more widespread allergy involving the face and extremities responded promptly to intramuscular injections of $125 \mathrm{mg}$. hydrocortisone acetate, but concentrations of less than that amount were ineffective.

Uveal Tract Disease.-Our first series included eleven cases treated with hydrocortisone acetate. The paradoxical results precluded any definite conclusions.

(a) Anterior Uveitis.-Two patients with iridocyclitis and one with low grade choroiditis were benefited by topical applications.

A fourth with a peri-vasculitis was improved by subconjunctival injection.

A patient with acute choroiditis involving the periphery had a drop in vision from $20 / 20$ to 20/70 after a subconjunctival injection of hydrocortisone acetate, but had a prompt rise to 20/30 after a subconjunctival injection of the same amount of cortisone. Later, subconjunctival cortisone failed to maintain the improvement, and her vision again decreased. At this point she was hospitalized and given a course of intravenous corticotropin and her sight improved.

Two other cases of anterior uveitis continued to progress despite applications of topical hydrocortisone, but one of these improved markedly and the other moderately with corticotropin. The former had previously failed to respond to 2 weeks' therapy with cortisone drops at another clinic.

(b) Chronic Posterior Uveitis.-Four cases were treated with subconjunctival injections of hydrocortisone acetate. The results were so slight that evaluation is difficult. One of them, who had had uveitis for over a year had been subjected to various forms of treatment, including cortisone topically and systemically, artificial induction of fever, corticotropin intravenously and intramuscularly, and isonicotinic acid. He had always become worse when given cortisone by whatever route, but corticotropin controlled the inflammation when given in maintenance doses once or more weekly. He had a questionable mild improvement after the combined subconjunctival and topical use of 
hydrocortisone acetate. He has recently been placed upon subconjunctival injections of free alcohol hydrocortisone, and his vision has improved from 20/50 to 20/30, with definite clearing of the vitreous. The beneficial effect of each injection of free hydrocortisone usually lasts about 3 weeks.

The free alcohol form was used in seven cases of chronic uveitis and in two cases of acute macular choroiditis. The two last mentioned responded immediately to the first subconjunctival injection of $8 \frac{1}{3} \mathrm{mg}$. Three of the seven chronic cases are well controlled by subconjunctival injections, and a fourth by oral doses (having had a questionable response to subconjunctival injections). A fifth case (who has Boeck's sarcoid) was improved by the subconjunctival injections. A sixth case (whose uveitis is associated with erythema nodosum) exhibited no response to the first subconjunctival injection and was placed on intravenous drips of corticotropin, to which he responded well. In the seventh case no improvement was seen after subconjunctival injections.

On the basis of this small series the free form of hydrocortisone appears to be superior to the acetate form in the treatment of uveitis. Since the effects of the free alcohol form are seen rapidly and last but a few days, and the acetate form acts more slowly over a longer period, the next step will be to try a mixture of both.

Orbital Pseudotumour.-One patient, whose successive attacks have responded to both corticotropin and cortisone employed systemically, has exhibited an excellent response to the free alcohol hydrocortisone taken orally. The initial dose was $100 \mathrm{mg}$., rapidly reduced to $25 \mathrm{mg}$., daily.

The response of various conditions to hormone therapy is set out in Table II, where an attempt is made to reconcile the results described in the literature.

TABLE II

RESPONSE OF CERTAIN EYE DISEASES TO STEROID HORMONE THERAPY

\begin{tabular}{|c|c|c|}
\hline Reaction & \multicolumn{2}{|c|}{ Condition } \\
\hline Response ... & $\begin{array}{l}\text { Lid allergies } \\
\text { Keratitis (superficial, non-specific) } \\
\text { Keratitis (herpes zoster, disciformis) } \\
\text { Keratitis (acne rosacea) } \\
\text { Keratitis (interstitial) } \\
\text { Keratitis (striate) } \\
\text { Keratitis (hypopyon) } \\
\text { Marginal ulcers } \\
\text { Some chemical burns }\end{array}$ & $\begin{array}{l}\text { Acute and subacute uveitis } \\
\text { Episcleritis } \\
\text { Scleritis (early) } \\
\text { Phlyctenular kerato-conjunctivitis } \\
\text { Vernal catarrh } \\
\text { Orbital cellulitis } \\
\text { Orbital pseudotumour } \\
\text { Optic and retrobulbar neuritis } \\
\text { Central serous retinopathy }\end{array}$ \\
\hline $\begin{array}{c}\text { Response followed } \\
\text { by relapse } \quad \ldots\end{array}$ & $\begin{array}{l}\text { Chronic inflammations of all ocular } \\
\text { tissues }\end{array}$ & Chronic allergies \\
\hline 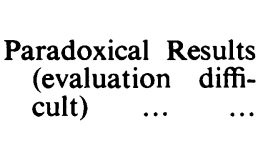 & $\begin{array}{l}\text { Keratitis profunda } \\
\text { Eales's disease } \\
\text { Stevens-Johnson syndrome } \\
\text { Mooren's ulcer } \quad \text { Herpes simplex }\end{array}$ & $\begin{array}{l}\text { Exophthalmos (various aetiologies) } \\
\text { Branch venous thrombosis } \\
\text { Secondary glaucoma } \\
\text { Ocular pemphigus } \\
\text { (dendritic ulcers) }\end{array}$ \\
\hline No Response & $\begin{array}{l}\text { Diabetic retinopathies } \\
\text { Retrolental fibroplasia } \\
\text { Scars } \\
\text { Central vein thrombosis } \\
\text { Deep scleritis Certain virus infe }\end{array}$ & $\begin{array}{l}\text { Degenerations-dystrophies } \\
\text { Retinitis pigmentosa } \\
\text { Cataract } \\
\text { Primary glaucoma } \\
\text { Optic atrophy } \\
\text { ctions of the globe }\end{array}$ \\
\hline
\end{tabular}


A suggested order of choice of hormones in various pathological conditions is shown in Table III, and dosage schedules that have been fourd efficient are set out in Table IV.

TABLE III

SUGGESTED ORDER OF USE

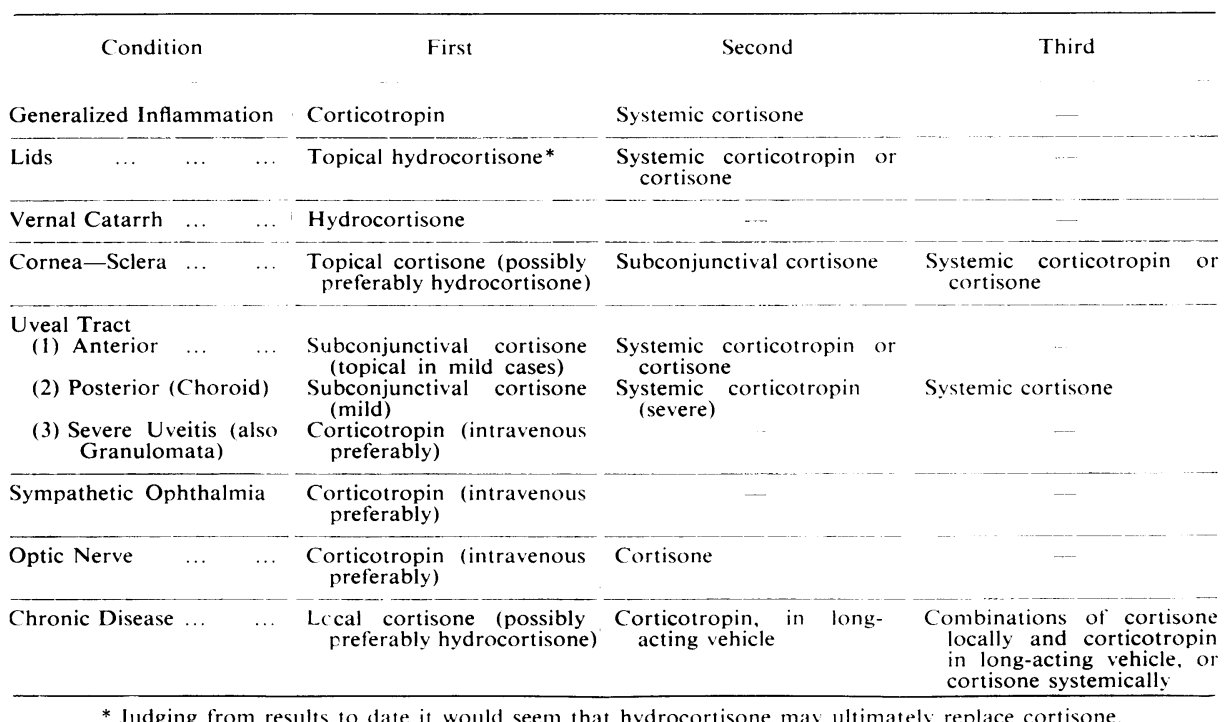

TABLE IV

DOSAGE SCHEDULES

Intramuscular: $20-40 \mathrm{mg}$. every 6 hours; optimal $25 \mathrm{mg}$. This level usually maintained for 10 days, after which it is gradually decreased, and discontinued after $10 \mathrm{mg}$. doses are reached.

Corticotropin Long-acting vehicles: $80-160 \mathrm{mg}$. daily: optimal $80 \mathrm{mg}$. Dose may be much less in the newer, more potent preparations. May be used twice daily during initial stages of acute disease, taper after about 10th day.

Topical: 0.5 and 2.5 per cent. suspensions available commercially (i.e.. 5 and $25 \mathrm{mg} . / \mathrm{ml}$.): optimal 0.5 per cent. $15 \mathrm{mg}$. $/ \mathrm{Gm}$. in ointment form.

Subconjunctival: $\frac{1}{3}, \quad \mathrm{ml}$. 2.5 per cent. suspension: every 3 to 14 days as indicated by progress of disease.

Cortisone

Systemic (oral or intramuscular): $300 \mathrm{mg}$. first day, $200 \mathrm{mg}$. next 2 days followed by $100 \mathrm{mg}$. for approximately 8 to 10 days, then taper off.

Oral: may require up to 25 per cent. greater dosage, divided into four daily doses.

Hydrocortisone Local and intramuscular: similar to cortisone.

Oral: 100-150 mg. daily, initially. 


\section{Summary and Conclusions}

Corticotropin and cortisone have proved to be valuable additions to the ophthalmic armamentarium. It must be emphasized that these are not last-minute agents, but efficient compounds whose maximum value is dependent upon their early use. The chief aim of all therapy is to cure an acute inflammatory or allergic (or traumatic) disease with a minimum of damage to the ocular tissue, at the same time preventing the development of a chronic process. The hormone selected must therefore be employed at an early stage in the disease. Experience has demonstrated that the final result depends upon the duration and severity of the disease process versus the potency, dosage, and length of treatment of the hormone. Hydrocortisone, the newest of the steroid hormones to be introduced to ophthalmology, still requires further research.

The intelligent use of these compounds requires recognition of the fact that corticotropin and cortisone are two different hormones, with two different modes of action. The fact that cortisone can be employed topically renders this the remedy of choice in the average case of superficial ocular disease. Deeper involvement may demand systemic therapy with either corticotropin or cortisone. Corticotropin employed as an intravenous drip over a period of 8 or more hours has so far proved the most effective systemic therapy. The introduction of the new high potency corticotropin gels has rendered ambulatory treatment possible in many patients who would formerly have required hospitalization. Combinations of local cortisone and systemic corticotropin (especially in a long-acting vehicle) or cortisone (especially in the oral form) can be employed profitably in the maintenance of chronic cases. All these preparations lend themselves to ambulatory treatment, with proper control. Complications rarely occur within the first 2 weeks of systemic treatment.

If the acute inflammatory process does not respond within a maximum of 48-72 hrs, one must then consider either increasing the dose or switching to the alternative hormone. It is unwise to risk damage to the eye by continuing a form of therapy which is not giving relief.

The presence of a positive culture or evidence of bacterial infection is an indication for the supplementary use of those antibiotics which will function in the presence of a normal or practically normal capillary permeability. Other supportive measures, such as the use of atropine and artificially induced fever, still have their place in treatment.

The fact that a chronic or subacute case will relapse upon the cessation of hormonal therapy is not a contraindication to its use. Such patients demand the full use of the ophthalmologist's skill in mapping out a maintenance programme which will combine the maximum safety with the maximum comfort or visual function.

The bulk of the corticotropin and all of the high potency corticotropin in long-acting vehicles used in this work was supplied by the Armour Research Laboratories through the courtesy 
of Drs G. W. Bissell and J. A. Hubata. A small amount was supplied by Parke-Davis and Company, through the courtesy of Dr. E. Vonderheide. All of the hydrocortisone and part of the cortisone were supplied by Merck and Company, Inc., through the courtesy of Dr. E. Alpert. A large amount of cortisone was also supplied by the Schering Corporation, through the courtesy of Dr. N. Heminway.

\section{REFERENCES}

Alpert, E. J. (1952). Personal communication.

AMERCIAN Medical Association (1952). "Adrenocorticotropic Activity of Placental Extracts " Editorial. J. Amer. med. Ass., 148, 1226.

ArendShORST, W., and FAlls, H. F. (1950). Arch. Ophthal., Chicago, 44, 635.

AsHTON, N., and CoOK, C. (1951). British Journal of Ophthalmology, 35, 708.

BAKER, B. L. (1949). "Pituitary-adrenal Function". In Symposium, ed. R. C. Christman (1951). American Association for the Advancement of Science, New York. and CASTOR, C. W. (1950). Anat. Rec., 106, 173.

Biegel, A. C. (1951). Arch. Ophthal., Chicago, 45, 258.

Cook, C., and MacDonald, R. K. (1951). British Journal of Ophthalmology, 35, 730.

DUKE-ELDER, S. (1951). Ibid., 35, 637.

Gonzalez Vanrell, F., Carriquiry, P., Conti, O., and Mussio Fournier, J. C. (1949). Dia méd., 21, 950.

Gordon, D. M. (1947). Amer. J. Ophthal., 30, 565.

(1948). Trans. Amer. Acad. Ophthal. Otolaryng., 52, 191.

(1952). Third ACTH Conference. Chicago, Illinois (not yet published). and Mclean, J. M. (1950). J. Amer. med. Ass., 142, 1271.

Koteen, H., Bousquet, F. P., McCusker, W. D., Baras, I., Wetzig, P., and Norton, E. W. D. (1951). Amer. J. Ophthal., 34, 1675.

LeOPOLd, I. H. (1951). Arch. Ophthal., Chicago, 46, 159.

- Purnell, J. E., Cannon, E. J., Steinmetz, C. G., and McDonald, P. R. (1951). Amer. J. Ophthal., 34, 361.

Lister, A., and Greaves, D. P. (1951). British Journal of Ophthalmology, 35, 725.

Mclean, J. M., Gordon, D. M., and Koteen, H. (1951). Trans. Amer. Acad. Ophthal. Otolaryng., 55, 565.

Michael, M., and Whorton, C. M. (1951). Proc. Soc. exp. Biol., N. Y., 76, 754.

Plotz, C. M., Blunt, J. W., and Ragan, C. (1950). Arch. Derm. Syph., Chicago, 61, 913.

Ragan, G., Howes, E. L., Plotz, C. M., Meyer, K., Blunt, J. W., and Lattes, R. (1950). Bull. N. Y. Acad. Med., 26, 251.

RandolPh, T. G., and Rollins, J. P. (1950). Ann. Allergy, 8, 626.

Rosen, D. A. (1952). "Effect of Intravenous Typhoid Vaccine on Adrenocortical Function". Wilmer Residents' Meeting, Baltimore.

Selye, H. (1950). " "Stress". ACTA, Inc., Montreal.

SMITH, R. (1952). Third ACTH Conference. Chicago, Illinois (not yet published).

STEEN, A. S. (1951). British Journal of Ophthalmology, 35, 741.

StefFEnSEN, E. H., and KuKORA, J. (1951). Amer. J. Ophthal., 34, 1665.

THORN, G. (1952). Third ACTH Conference. Chicago, Illinois (not yet published).

ThORPE, H. E. (1951). "Proc. 2nd Clinical ACTH Conf.", ed. J. R. Mote, vol. 2, p. 340. Churchill, London.

TOMPSETT, R. (1952). Personal communication.

Wolfson, W. (1952). Third ACTH Conference. Chicago, Illinois (not yet published).

Woods, A. C. (1951). Amer. J. Ophthal., 34, 945. (1952). Wilmer Residents' Meeting. Baltimore. and WooD, R. M. (1951). "Proc. 2nd Clinical ACTH Conf.", ed. J. R. Mote, vol. 1, p. 455. Churchill, London. 